\title{
Carboxyhaemoglobin and pulmonary epithelial permeability in man
}

\author{
J GARETH IONES, BD MINTY, D ROYSTON, JP ROYSTON
}

From the Divtsions of Anaesthesia and of Computing and Statistics, Clinical Research Centre, Northwick Park Hospital, Harrow, Middlesex

ABSTRACT The effect of cigarette smoke exposure on pulmonary epithelial permeability was studied in 45 smokers and 22 non-smokers. An index of cigarette smoke exposure was obtained from the carboxyhaemoglobin concentration ( $\mathrm{HbCO} \%)$. Pulmonary epithelial permeability was proportional to the half-time clearance rate of technetium-99m-labelled diethylene triamine pentacetate ( ${ }^{99}$ Tc DTPA) from lung to blood $\left(T^{1 / 2}{ }_{L B}\right)$. The relationship between $T^{1 / 2}{ }_{L B}$ and $\mathrm{HbCO} \%$ was hyperbolic in form and the data could be fitted to the quadratic formula

$$
\mathrm{T} 1 / 2_{\mathrm{LB}}=a_{0}+\frac{a_{1}}{\mathrm{HbCO}}+\frac{a_{2}}{\mathrm{HbCO}^{2}}
$$

where the parameters $a_{0}, a_{1}$, and $a_{2}$ represent respectively the asymptotic $T^{1 / 2}{ }_{L B}$ value at large carboxyhaemoglobin values and the slope and shape of the curve. The values of these parameters were $a_{0} 4.4(2.6), a_{1}=77.8(15.5)$, and $a_{2}-25.5(9.7)(\mathrm{SE})$. This is the first demonstration of a dose-response relationship between carboxyhaemoglobin and an increased permeability of the lungs in man and provides a technique for identifying the roles of carbon monoxide and other cigarette smoke constituents in causing increased pulmonary epithelial permeability.

The association between cigarette smoking and lung disease is well known. ${ }^{1}$ In recent years an association has been shown between the numbers of cigarettes smoked and the functional effects on the lung ${ }^{2}$ but a dose-response curve of cigarette smoke exposure against a functional effect on the lung has yet to be produced. Cigarette smoke exposure is usually expressed in terms of pack years of cigarette consumption and the functional effects on the lung are commonly expressed in terms of changes in the results of tests of airway patency. It is now becoming realised that an accurate estimate of lung exposure to smoke cannot be obtained from questionnaires indicating cigarette consumption and depth of smoking. ${ }^{4}$ Furthermore, the changes in airway patency are slow in onset and are affected by the age of the subject and by variations in bronchomotor tone. The concentration of carboxyhaemoglobin in blood provides a more accurate index of exposure of the lung to cigarette smoke ${ }^{56}$ than quantitation of the

Address for reprint requests: Dr J Gareth Jones, Clinical Research Centre, Northwick Park Hospital, Harrow, Middx HA1 3 UJ. amount of cigarettes smoked and can be used to establish a dose-response relationship. The carboxyhaemoglobin index of cigarette smoke exposure, although well documented, has not until now been correlated with any test of pulmonary function. We have recently described a new approach to the problem of evaluating the effects of smoking on the function of the lung based on the permeability of the pulmonary epithelium to the labelled chelate technetium-99m diethylene triamine pentacetate $\left({ }^{99} \mathrm{mTc}\right.$ DTPA). ${ }^{78}$ Using this technique we have shown that cigarette smokers have significantly more permeable lungs than nonsmokers. ${ }^{79}$

In this study we have examined the relationship between carboxyhaemoglobin and pulmonary epithelial permeability in a group of healthy subjects, some of whom were cigarette smokers and others non-smokers.

\section{Methods}

The study was approved by the Northwick Park Hospital ethical committee. The subjects, all mem- 
bers of the staff of an urban general hospital, included 45 symptomless cigarette smokers aged 19-65 (mean 31) years and 22 healthy non-smokers aged 19-55 (mean 35 ) years.

In each subject an index of pulmonary epithelial permeability was obtained by the technique previously described. ${ }^{7-9}$ The supine subjects first breathed for three minutes an aerosol of ${ }^{99 m} \mathrm{Tc}$ DTPA in saline (mass median diameter $0.9 \mu \mathrm{m}$, geometric standard deviation $1 \cdot 8$ ). With the subject breathing air, the clearance from lung into blood of the labelled chelate was then measured with a collimated scintillation detector positioned over the right upper lung field. A second detector, positioned over the thigh, measured the rate of increase of labelled chelate transferred from the lung to the blood and tissue in that field. Corrections were made for the contribution of radioactivity in pulmonary vascular tissue to the lung field detector. ${ }^{78}$ This was achieved by subtracting a proportion of the thigh counts from the lung counts. This proportion was derived after the intravenous injection of ${ }^{99 \mathrm{~m}} \mathrm{Tc}$ DTPA, which increased the radioactivity in the counting fields of the two detectors (fig 1) in proportion to the vascular tissue in the two fields. Extrapolation to the time of injection produced the increment of radioactivity $(a)$ in the lung and $(b)$ in the thigh fields. The radioactivity curve from the thigh was multiplied by $a / b$ to produce the background correction to be subtracted from the lung curve. The index of pulmonary epithelial permeability was expressed as the halftime clearance in minutes $\left(T^{1 / 2}{ }_{L B}\right)$ of the corrected curve of tracer passing from lung to blood.
Venous blood samples were taken from each sub $\overrightarrow{\overline{\vec{A}}}$ ject for measurement of carboxyhaemoglobirg which was measured spectrophotometrically wit the IL 282 Co-oximeter. ${ }^{10}$ Blood samples were obtained at $\mathbf{2 0 . 0 0}$ hours or, in the case of night-shi角 workers, at 07.00 hours at the end of the shift Blood samples from smokers were obtained one minute after they had smoked a cigarette. The meaP carboxyhaemoglobin value was derived from blood samples obtained on two separate occasions. In further study the repeatability of the carboxy产 haemoglobin value was determined from measi urements made in four subjects at weekly interva 5 for three weeks; in each case the blood was sampled. in the late evening.

\section{Results}

The relationship between $T^{1 / 2}$ LB and carboxys haemoglobin (HbCO) appeared hyperbolic in forr (fig 2). A quadratic equation of the type

$$
\mathrm{T}^{1 / 2}{ }_{\mathrm{LB}}=a_{0}+\frac{a_{1}}{\mathrm{HbCO}}+\frac{a_{2}}{\mathrm{HbCO}^{2}}
$$

was fitted to the data, where the coefficient $a_{0}$ reps resents the asymptotic $T^{1 / 2} \mathbf{L B}_{\mathrm{LB}}$ value at large carboxy haemoglobin values and $a_{1}$ and $a_{2}$ are slope anf shape parameters. The values of these parameter (with their standard errors) were $a_{0} 4 \cdot 4(2 \cdot 6), a_{1} 77 \cdot \frac{\vec{E}}{8}$ (15.5), and $a_{2}-25.5(9.7)$. The data clearly dis played a skew distribution about the fitted curve The above equation was satisfactorily refitted, on

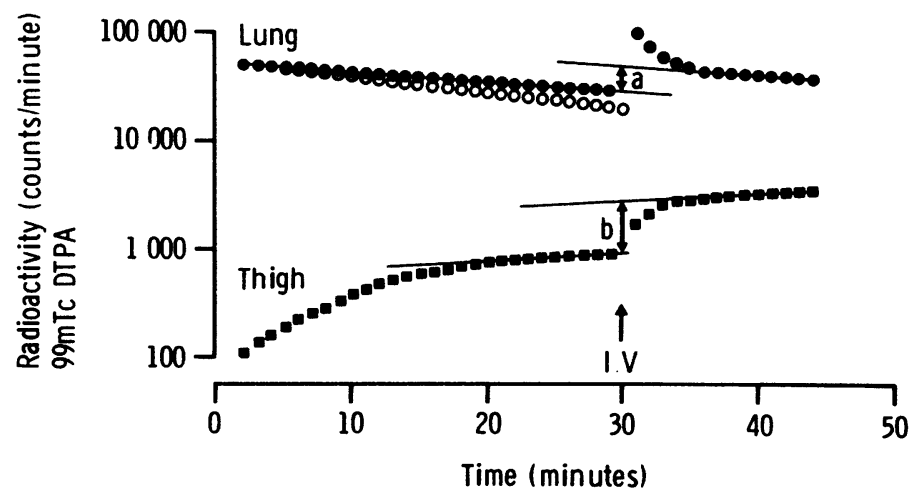

Fig 1 Method of correcting the lung clearance curve. Detectors are placed over lung and thigh and the change in radioactivity is measured after the subject has breathed ${ }^{99 \mathrm{~m} T c}$ DTPA aerosol. At 30 minutes an intravenous $50-\mu \mathrm{Ci}$ dose of ${ }^{99 \mathrm{~m} T c}$ DTPA is given and the subsequent curves are extrapolated as shown to produce the intercepts $a$ and $b$. The thigh curve is multiplied by $a / b$ and subtracted from the lung curve to produce the corrected lung clearance curve (open circles). 


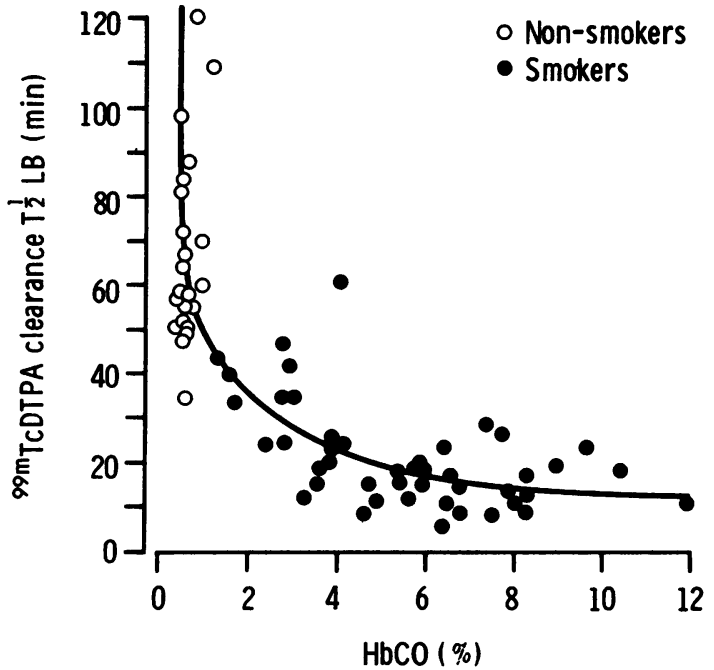

Fig 2 Relationship between carboxyhaemoglobin concentration (HbCO\%) and half-time clearance of ${ }^{99 \mathrm{~m} T c}$ DTPA from lung to blood $\left(T^{1 / 2}{ }_{2 B}\right)$ in smokers and non-smokers (curve calculated with the equation given under "Results").

Carboxyhaemoglobin values (\%) measured at weekly intervals in four smokers

\begin{tabular}{llrl}
\hline Subject & \multicolumn{2}{l}{ Week } & \\
\cline { 2 - 4 } & 1 & 2 & 3 \\
\hline A & 3.6 & 3.5 & $5 \cdot 2$ \\
B & 9.5 & 10.8 & 8.6 \\
D & 9.3 & 8.5 & $8 \cdot 4$ \\
D & 6.5 & 6.1 & 5.4 \\
\hline
\end{tabular}

the assumption that the distribution was log normal, with the help of the generalised linear interactive modelling computer program GLIM $3^{11}$ with a special numerical fitting method. ${ }^{12}$ The resulting fit explained a highly significant proportion of the variation in the data $(p<0.001)$.

The standard deviation of scatter about the fitted curve in log units was 0.41 , and the approximate 95\% limits for $\mathrm{T}^{1 / 2_{\mathrm{LB}}}$ at a fixed carboxyhaemoglobin value were $0.44 \times \mathrm{T}^{1 / 2_{\mathrm{LB}}}$ for the lower limit and 2.3 $T 1 / 2_{L B}$ for the upper limit.

The $T^{1 / 2}{ }_{L B}$ data for the cigarette smokers was plotted against cigarette consumption expressed as pack years (fig 3). This representation of the data also shows a relationship between the two variables which is of hyperbolic form. The data are very nonuniformly distributed, however, so that the whole range of $T^{1 / 2} \mathrm{LB}$ values is found in the $0-15$ pack-year range. In fact, some of the subjects who had been smoking for only two years had the shortest $T^{1 / 2} \mathrm{LB}$.

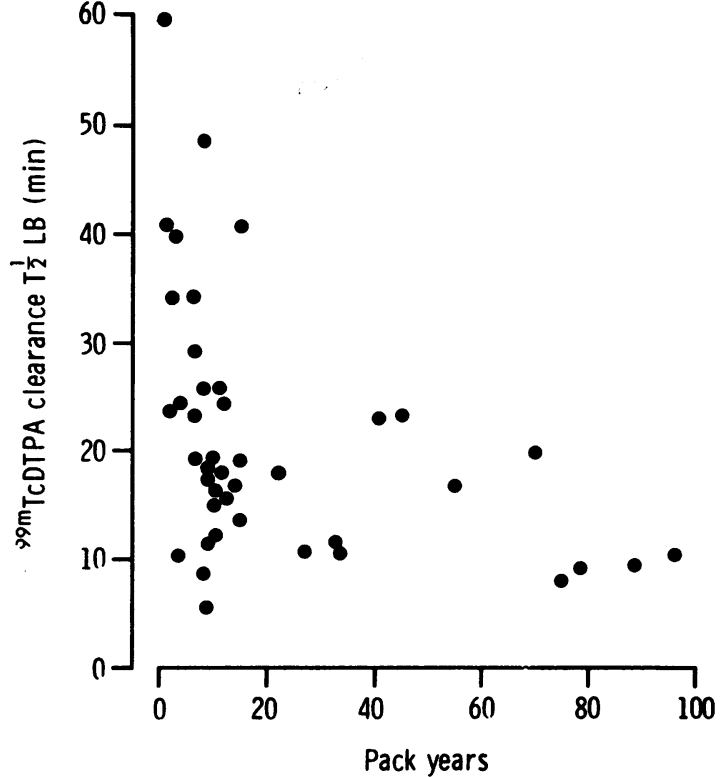

Fig 3 Relationship between pack years and half-time clearance of ${ }^{99 \mathrm{~m} T C}$ DTPA from lung to blood $\left(T^{1 / 2}{ }_{L B}\right)$ for cigarette smokers.

The variability of carboxyhaemoglobin concentrations in the same subject over a three-week period was examined by taking blood samples at 20.00 hours at weekly intervals. The results are shown in the table.

\section{Discussion}

The study shows for the first time a close correlation in man between exposure of the lungs to cigarette smoke, represented by concentrations of carboxyhaemoglobin, and an increase in permeability of the pulmonary epithelium measured by the rate of disappearance of ${ }^{99 m}$ Tc DTPA from the lungs. The carboxyhaemoglobin values obtained in the nonsmoking subjects were in most cases higher than would be expected from endogenous carbon monoxide production alone. ${ }^{13}$ No attempt was made to isolate the latter individuals from their normal exposure to atmospheric pollution from cigarette and vehicle exhaust smoke. The significant correlation between carboxyhaemoglobin and $T^{1} /{ }_{L B}$ does not imply that carbon monoxide itself is the cause of this effect on lung function, although we have previously shown that acute exposure to high concentrations of carbon monoxide produces lung damage in animals. ${ }^{14}$

Cigarette smoke is a complex mixture of many toxic constituents, ${ }^{1}$ but many of these constituents 
are likely to vary in direct proportion to the carbon monoxide content. There have been considerable reductions in yields of tar, nicotine, and carbon monoxide from cigarettes manufactured in recent years but the reduction in carbon monoxide has been much less than the reduction of nicotine and tar. ${ }^{13}$ Our techmique provides an opportunity to examine the effects of carbon monoxide exposure alone on pulmonary epithelial perneability and thus establish the respective roles of carbon monoxide and other cigarette smoke constituents in producing an increase in the epithelial permeability of the lung. In this way a new approach may be made to solve the problem of the design of a safe cigarette, and we have already shown that nicotine itself does not produce any change in lung permeability in nonsmokers. ${ }^{7}$

The poor correlation between $T^{1 / 2} 2_{L B}$ and pack years is not surprising if the permeability defect is induced quite soon after a person has taken up smoking. Some subjects who had been smoking for only two years had the shortest $T^{1 / 2}{ }_{L B}$. There is only a little information in man about the rate of change of pulmonary epithelial permeability after a change in smoking habits. We have noted a statistically significant improvement in the permeability index of the lung only 24 hours after cessation of smoking. ${ }^{9}$ In two of these smokers, who had ceased to smoke for three weeks, we noted that within 24 hours of their resuming smoking the $T^{1 / 2}{ }_{L B}$ fell to the value found before they had stopped. In two non-smokers who took up smoking for three days there was an increase in epithelial permeability which corresponded to that predicted from the relation between carboxyhaemoglobin and $\mathrm{T}^{1 / 2} \mathrm{LB}^{16}$ In view of the likelihood that the onset of increased pulmonary epithelial permeability is rapid, the time weighting used in the derivation of pack years may not be relevant in estimating the effect of cigarette smoke exposure on lung permeability.

Other workers have shown an increase in permeability of the respiratory epithelium in experimental animals after exposure to cigarette smoke. ${ }^{17} 18$ They used the tracer molecule horseradish peroxidase and, using electron microscopy, showed that the electron-dense molecule penetrated the tight junctions of the pulmonary epithelium in animals exposed to smoke and that increasing the dose of smoke increased the severity of the injury. ${ }^{17}$ They also found that the injury was rapidly initiated by acute exposure of guinea-pigs to as little as $\mathbf{1 0 0}$ puffs of cigarette smoke in 33 minutes, and that after such a brief exposure the microscopic injury appeared to have resolved after 12 hours. ${ }^{18}$ This was a much more rapid rate of recovery than we have reported in man after cessation of smoking..$^{9}$ No information is available about the amount of carbo $\overrightarrow{\overrightarrow{\vec{A}}}$ monoxide exposure of these animals but in expert ments carried out in our laboratory with a similef system the carboxyhaemoglobin concentration was over $20 \%$.

It is of interest that the $T 1 / 2{ }_{L B}$ tends to asymptote at high concentrations of carboxyhaemoglobin. This might imply that the small low-molecular-weight tracer used in our study is not sensitive to further increases in lung permeability or that no furtheff increase in permeability occurs with increasing smoke exposure. Both of these hypotheses could be tested with a tracer molecule of larger moleculapp weight. The relationship that we have found between carboxyhaemoglobin and $\mathrm{T}^{1} / \mathbf{2}_{\mathrm{LB}}$ also indicatef the degree of reduction in smoke exposure neces sary to achieve a beneficial effect on the defect in pulmonary epithelial permeability, either through reduction in the number of cigarettes smoked of through a change from mid-tar to low-tar cigarettes. So far we have been unable to show a beneficia effect on smokers changing from mid-tar to low-tar cigarettes. This was because the fall in carboxpe haemoglobin from $8 \cdot 1 \%$ to $7.2 \%$ was insufficient at that part of the curve of $\mathrm{T}^{1 / 2} \mathrm{LB}_{\mathrm{LB}}$ plotted againg carboxyhaemoglobin to be reflected in an increase 苗 the $T^{1 / 2}{ }_{L B} \cdot{ }^{19}$

The association between carboxyhaemoglob竞 concentrations and disorders of vessel walls and plasma volume ${ }^{2021}$ is well documented but this is the first demonstration of a dose-response relationship between carboxyhaemoglobin and pulmona epithelial permeability in man.

\section{References}

' Woolcock AJ, Berend N. The effects of smoking on the lungs. Aust NZ J Med 1977;7:649-62.

${ }^{2}$ Burrows B, Knudson RJ, Cline MJ, Lebowitz MP Quantitative relationships between cigarette smoking and ventilatory function. $A m$ Rev Respir Dis 1977;115:195-205.

${ }^{3}$ Beck GJ, Doyle CA, Schachter EN. Smoking and lung function. Am Rev Respir Dis 1981;123:149-55.

4 Vogt TM, Selvin S, Hulley SB. Comparison of biochemio cal and questionnaire estimates of tobacco exposure Prev Med 1979;8:23-33.

5 Vessey CJ, Saloojee Y, Cole PV, Russell MAH. Blood carboxyhaemoglobin, plasma thiocyanate, and cigarette consumption: implications for epidemiologe cal studies in smokers. Br Med J 1982;284:1516-8.

- Wald NJ, Idle M, Boreham J, Bailey A. Carbon monox ide in breath in relation to smoking and carboxy haemoglobin levels. Thorax 1981;36:366-9.

7 Jones JG, Minty BD, Lawler P, Hulands GH, Crawle JCW, Veall N.Increased alveolar epithelial permeabil ity in cigarette smokers. Lancet 1980;i:66-8. 
${ }^{8}$ Jones JG, Minty BD, Royston D. The physiology of leaky lungs. Br J Anaesth 1982;54:705-21.

${ }^{9}$ Minty BD, Jordan C, Jones JG. Rapid improvement in abnormal pulmonary epithelial permeability after stopping cigarettes. Br Med J 1981;282:1183-6.

10 Dennis RC, Valeri CR. Measuring percent oxygen saturation of hemoglobin, percent carboxyhemoglobin and methemoglobin and concentrations of total hemoglobin and oxygen in blood of man, dog and baboon. Clin Chem 1980;26:1304-8.

${ }^{11}$ Royal Statistical Society. The generalised linear interactive modelling system. Release 3. Oxford: Numerical Algorithms Group, 1978.

12 Royston JP. Fitting with lognormal or power-normal errors. Glim newsletters. Issue No 5. Oxford: Numerical Algorithms Group, 1981:21-6.

${ }^{13}$ Coburn RF, Blakemore WS, Forster RE. Endogenous carbon monoxide production in man. $J$ Clin Invest 1963;42:1172-8.

${ }^{14}$ Fein A, Grossman RF, Jones JG, Hoeffel J, McKay D. Carbon monoxide effect on alveolar epithelial permeability. Chest 1980;78:726-31. is Fairweather FA, Carmichael IA, Phillips GF, Copeland GKE. Changes in the tar, nicotine and carbon monoxide yields of cigarettes sold in the United Kingdom. Health Trends 1981;3:77-81.

${ }^{16}$ Minty BD, Royston D, Jones JG. The effect of nicotine on pulmonary epithelial permeability in man. Thorax 1982;37:791.

${ }^{17}$ Boucher RC, Johnson J, Inoue S, Hulbert W, Hogg JC. The effect of eigarette smoke on the permeability of guinea pigs' airways. Lab Invest 1980;43:94-100.

1s Hulbert WC, Walker DC, Jackson A, Hogg JC. Airways permeability to horseradish peroxidase in guinea pig: the repair phase after injury by cigarette smoke. $A m$ Rev Respir Dis 1981;123:320-6.

${ }^{19}$ Minty BD, Royston D, Jones JG. Relationship between pulmonary epithelial permeability and HbCO. Thorax 1981;36:709.

${ }^{20}$ Parving $\mathrm{HH}$. The effect of hypoxia and carbon monoxide exposure on plasma volume and capillary permeability to albumin. Scand J Clin Lab Invest 1972;30:49-56.

${ }^{21}$ Astrup P. Some physiological and pathological effects of moderate carbon monoxide exposure. Br Med J 1972;iv:447-52. 